THE PERSONALITY CHARACTERISTICS OF HIGH SCHOOI MALE GYMNASTS

\title{
APPROVED :
}
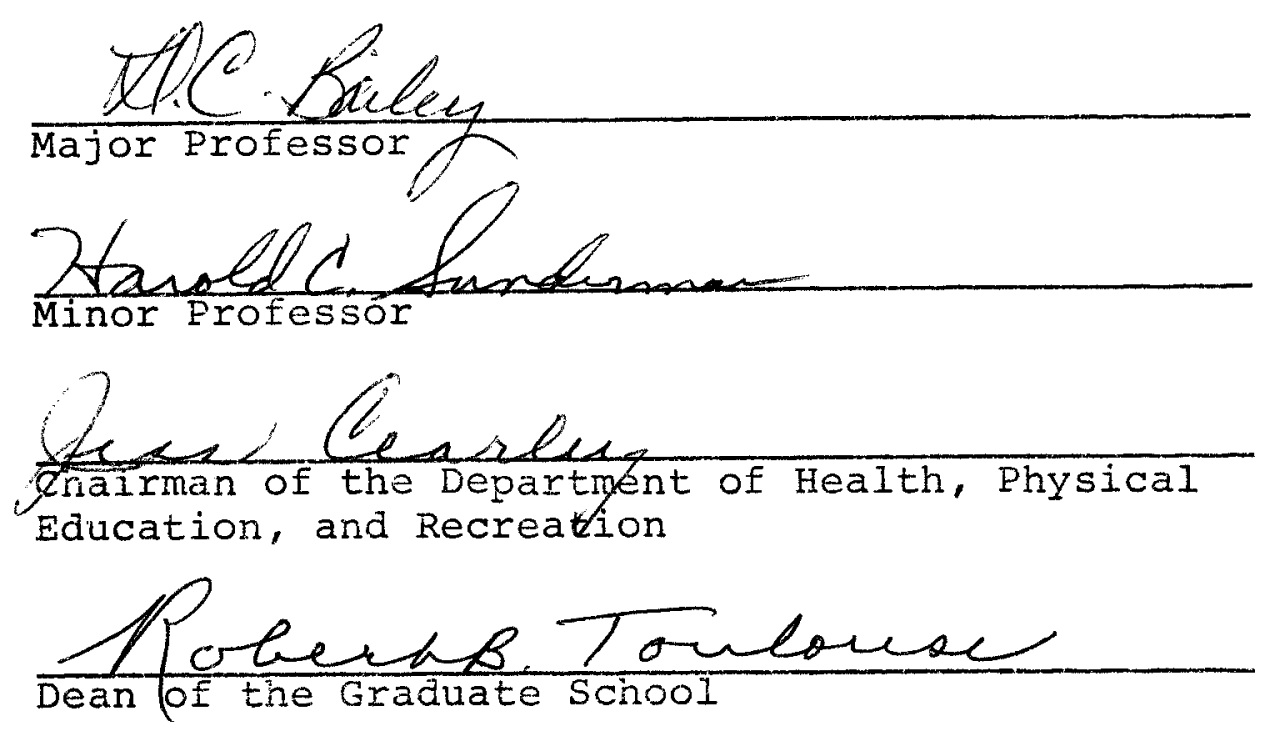
Bennington, Gary L., The Personality Characteristics of High School Male Gymnasts. Master of Science (Physical Education), May, 1972, 44 pp., 2 tables, bibliography, 40 titles.

The problem of this investigation was concerned with determining the personality characteristics of high school male gymnasts and comparison of these characteristics with those of football participants and non-athletes.

The purpose of this study was to examine the relationship between the personality characteristics of high school male gymnasts and the personality characteristics of high school football athletes and non-athletes. An attempt was made to answer three specific questions:

I. Do personality differences exist between the gymnastic group and the non-athletic group?

II. Do personality differences exist between the gymnastic group and the football group?

III. Do personality differences exist between the football group and the non-athletic group?

Ninety male high school subjects, ages fifteen through eighteen years, were utilized in this study. Thirty gymnasts, thirty football participants, and thirty non-athletes, selected from two high schools, served as subjects. 
The instrument of personality measurement utilized was the Ir. - Sr. High School Personality Questionnaire developed by Raymond B. Cattell. Fourteen factors were measured by the questionnaire.

A one-way, completely randomized analysis of variance using the $F$ ratio was applied to the group standard score means on fourteen personality factors measured by the questionnaire. Newman-Keuls multiple comparisons test was applied to the mean scores to determine the exact location of significant differences between groups on each of the fourteen personality characteristics measured.

The results of this investigation indicated (1) that the gymnastic group was significantly more intelligent than the non-athletic group at the .01 level of confidence, that there were no significant personality differences between the gymnastic group and the football group, (3) that the football group was significantly more intelligent than the non-athletic group at the .01 level of confidence, and (4) that the three groups were not significantly different on thirteen of the fourteen personality factors measured. The conclusions drawn from the findings of this study were (1) that high schooi gymnasts were significantly more intelligent than high school non-athletes, (2) that there were no significant differences between high school gymnasts and high school football participants on intelligence, (3) that high school football participants were significantly 
more intelligent than high school non-athletes, and (4) that groups of individuals appear to be more alike than different in their personality characteristics.

Recommendations for further research in this area were (1) that more high school state and national championship level gymnasts should be included in future studies, (2) that the non-athletic group should be limited to individuals who have had no instruction in gymnastics, and (3) that a different instrument of personality measurement should be used in future studies to determine whether the results of the present study prevail. 
THE PERSONALITY CHARACTERISTICS OF HIGH SCHOOL MALE GYMNASTS

\title{
THESIS
}

Presented to the Graduate Council of the North Texas State University in Partial Fulfillment of the Requirements

For the Degree of

MASTER OF SCIENCE

By

\author{
Gary L. Bennington, B.S. \\ Denton, Texas
}

May, 1972 
TABLE OF CONTENTS

LIST OF TABLES . . . . . . . . . . . . . . . . . . Page Chapter

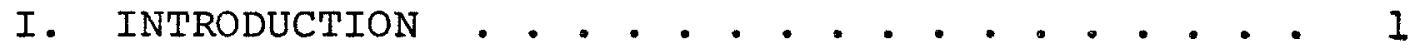

Statement of the Problem

Purpose of the Study

Definition of Terms

Limitations of the Study

II. REVIEW OF LITERATURE . . . . . . . . . . . 8

III. PROCEDURES . . . . . . . . . . . . . . 20

Selection of Subjects

Selection of Tests

Experimental Design

Analysis of Data

IV. ANALYSIS OF THE DATA . . . . . . . . . 25

Comparison with other Studies

V. SUMMARY, CONCLUSIONS, AND RECOMMENDATIONS . . 33

Summary

Findings

Conclusions

Recommendations

APPENDIX .................... 38

BIBLIOGRAPHY .................. 41 


\section{LIST OF TABLES}

Table

Page

I. Group Means of Standard Scores, Standard Deviations, and $F$ Ratios for the Three Groups on the Fourteen Factors Measured . . . . . . . . . . . . 26

II. Group Means of Standard Scores, Mean Difference, and Newman-Keuls Range Product on Factor B . . . . . . . . . . 27 


\section{CHAPTER I}

\section{INTRODUCTION}

Prior to the Greek civilization and until the present time, gymnastics in some form has contributed to man's culture. Early gymnastics was somewhat informal and the activities were usually performed in conjunction with religious festivities (4). Today, gymnastics consists of various apparatus activities and tumbling skills; however, the beauty of body form is still ultimate in gymnastics. Whether through his physical awareness in participation or through his psychological interpretation of aesthetic beauty, man and his culture have received many benefits and much enjoyment from gymnastics (5).

Gymnastics is an extremely demanding sport. Hours of practice are required of the gymnast each day. Gymnastics, like many sporting activities, demands a skill of execution which the good performer must display. This skill of execution comes partly from innate ability, physical development, and increased learning; however, it also comes from dedication and a love of the sport which enables the performer to submit himself to the type of mental and physical sacrifice and discipline prerequisite for success in gymnastics. Unlike many sports, both team and individual, which subject 
their participants to varying amounts of suffering, gymnastics is strictly an individual sport, and the sacrifices and pain experienced by the gymnast are induced not by another performer but by himself and a piece of equipment. Disregarding the usual discomforts associated with gymnastics and most sporting activities, this equipment induces pain only when the gymnast makes a mistake; therefore, any physical discomfort he experiences is initiated by his own performance. Many individuals find this to be unbearable and end their gymnastic involvement at a very early stage; however, those few who seem to be able to endure the situation, indeed, enjoy it. In many instances, it is a select few who choose gymnastics as their activity and pursue it with an insatiable desire for complete mastery of its skills. We may question why some are capable of success in gymnastics and some are not. Certainly, physical abilities and Iimitations are factors which cannot be ignored. Without adequate physical capabilities or available potential, it would appear reasonable to assume that success would not be forthcoming in an activity such as gymnastics; however, many researchers, coaches, and physical educators working with participants in varied and selected sports activities are in agreement that physical factors alone are not the only ones to be given consideration. The importance of mental or psychological factors also serves a beneficial role in an individual's success in sports and as such 
cannot be dismissed without adequate consideration. Research has indicated that psychological variables have a marked effect upon a person's performance (2). These variables can inhibit or enhance an individual's performance in any sporting activity.

In the same manner that an individual exhibits physical characteristics which are unique, he also exhibits psychological characteristics in a way unique to himself. Many individuals display similar traits; however, each person is unique.

Researchers, for many years, have sought to categorize individuals and groups of individuals according to personality traits or characteristics which are measurable. Certainly, this is only one means of classification; however, this method can be invaluable when attempting to discover similarities and differences among people and the groups they represent. For years coaches and physical educators have become increasingly aware of and interested in the psychological aspects of sports participation and the implications involved. More research is being devoted to the psychological aspects of sport than ever before in an attempt to understand more completely their role in sports participation (3). Likewise, more research is forthcoming in personality assessment of select athletic groups for a more complete understanding of the psychological aspects encountered during participation. 
Statement of the Problem

Research indicates that athletes exhibit or possess personality traits which are different from those of nonathletes (3). Likewise, athletes in a particular sports activity vary in their personality arrangement from athletes engaged in another sports activity. Due to these indicated differences, it would seem beneficial for coaches and physical educators to have a better knowledge and understanding of the personality traits that exist in individuals choosing selected sports activities. The psychological aspects of sports participation can be extremely important to success in athletics and, therefore, should not be overlooked (7). More research of this type is needed in the area of gymnastics.

Purpose of the Study

The purpose of this study was to examine the relationship between the personality characteristics of high school male gymnasts and the personality characteristics of high school football athletes and non-athletes. An attempt was made to answer three specific questions:

I. Do personality differences exist between the gymnastic group and the non-athletic group?

II. Do personality differences exist between the gymnastic group and the football group? 
III. Do personality differences exist between the football group and the non-athletic group?

$$
\text { Definition of Terms }
$$

Gymnastics refers to the six gymnastic events of Olympic competition. They are the still rings, parallel bars, horizontal bar, side horse, long horse vaulting, and floor exercise.

Gymnast refers to anyone on a high school gymnastics team or in a club organization whereby he competes with members of other high school gymnastic teams or club organizations.

Varsity football athlete refers to anyone on the football team of the two high schools represented. Non-athlete refers to anyone enrolled in boys' physical education but not involved in any varsity sport for the 1971-72 school year.

Personality is "that which tells what a man will do when placed in a given situation" (1, p. 25).

Personality Inventory is an instrument used in an attempt to measure selected personality traits by presenting a selection of items or questions to which the subject may respond to various alternatives. The instrument may be scored in an attempt to measure several different personality characteristics $(1, \mathrm{p} .69 ; 6, \mathrm{p} .52)$. 
Limitations of the Study

1. The gymnastic groups was limited to those male individuals specifically selected from two high schools.

2. The football group was limited to those male individuals engaged in competitive football at two high schools.

3. The non-athletic group was limited to those male individuals enrolled in boys' physical education at two high schools. All of the non-athletes had been exposed to some gymnastics instruction in the required physical education program. 


\section{CHAPTER BIBLIOGRAPHY}

1. Cattell, Raymond B., The Scientific Analysis of Personality, Baltimore, Maryland, Penguin Books, Inc., 1965.

2. Cratty, Bryant J., Movement Behavior and Motor Learning, Philadelphia, Lea and Febiger, 1967.

3. , Psychology and Physical Activity,

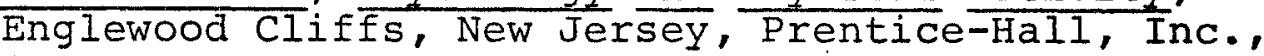
1968 .

4. DeCarlo, Tom, Handbook of Progressive Gymnastics, Englewood Cliffs, New Jersey, Prentice-Hall, Inc., 1963.

5. Duncan, Ray O., Introduction to Physical Education, New York, The Ronald Press Company, 1960 .

6. Edwards, Allen L., The Measurement of Personality Traits by Scales and Inventories, New York, Holt, Rinehart and Winston, Inc., 1970.

7. Oxendine, Joseph B., Psychology of Motor Learning, New York, Appleton-Century-Crofts, 1968 . 


\section{CHAPTER II}

\section{REVIEW OF LITERATURE}

Much has been written about the use of questionnaires and inventories to measure personality traits (5). Many researchers condemn them because they feel that this type of measurement is incapable of truly measuring personality traits; however, many researchers utilize these questionnaires and inventories with a realization that, when used properly, they can offer much insight into a person's personality structure. As Morgan (14) points out, before physical educators and coaches can claim that physical education and exercise contribute to desirable psychological development, some type of psychological measurement is necessary. Nelson and langer (15) indicate that inventories and questionnaires are not always the best means for assessing personality traits nor is a complete answer to the problem always given; however, they do supply much useful information that will be helpful in predicting outcomes and guiding an individual to a happier life as a result of his athletic experiences. The importance of psychological aspects of sport participation is noted by Ogilvie (18) when he suggests that those persons demonstrating physical greatness receive some special psychological attention. He 
states further that this becomes extremely significant when athletic greatness is forthcoming. However one may feel about personality assessment, it appears that questionnaires and inventories can serve coaches and physical educators in attempting to understand more completely potential and established participants in various sports activities.

A review of the literature revealed many studies which sought to compare personality characteristics of athletic groups to other athletic groups or groups of non-athletes by the administration of personality questionnaires. Most of these studies dealt with the college-aged adult, and it appears that less has been done on the high school level in attempting to assess personality traits of athletes.

Thune (27) wanted to determine the personality of a group of weightlifters. Using 100 male weightlifters at a YMCA and 100 different YMCA male athletes, he administered a personality inventory in an effort to determine group differences in their attitudes and dispositions of personality. Statistically significant differences between the weightlifters and other athletes were found in three of the categories: present health, self-confidence, and manlyindividualistic. It was concluded that weight training appeals to a group that differs in interests, attitudes, and personality from the other YMCA members. The inventory items indicated that the weightlifters felt more strongly that their health had improved. They were shy, lacked 
self-confidence, and were dissatisfied with losing in the traditional physical activities. They wished to be strong and dominant.

Johnson, Hutton, and Johnson (7) conducted a study to determine the personality traits of some champion athletes. Twelve national champions or All-Americans in their respective sports were measured by two projective personality tests, a group Rorschach and the House-Tree-Person test. An analysis of the data revealed distinct personality traits of these athletes. Extreme aggression, uncontrolled affect (emotions lacking strict controls), high and generalized anxiety, high level of intellectual aspiration, and exceptional feelings of self-assurance were five of the most outstanding personality characteristics of these athletes, four of which were football players, two of which were lacrosse players, two of which were wrestlers, two of which were boxers, one was a track man, and one a rifle marksman. They also had an unusual concern for physical power and physical perfection and were able to concentrate personality resources upon their desired objectives.

In a study by Booth (2), the Minnesota Multiphasic Personality Inventory (MMPI) was used to compare the personality ratings of freshman athletes and freshman nonathletes, varsity athletes and upper-class non-athletes, varsity athletes and freshman athletes, athletes only in team sports and athletes only in individual sports, athletes 
only in team sports and athletes in both team and individual sports, athletes in only individual sports and athletes in both team and individual sports, and finally, athletes who were judged to be poor competitors and athletes who were judged to be good competitors. A selection of test items from the MMPI to discriminate between poor and good competitors was a secondary purpose of the study. The nonathletes scored significantly higher than the athletes on the interest (Mf) variable. In relation to the anxiety (A) variable, freshman athletes, freshman non-athletes, and upper-class non-athletes scored significantly higher than the varsity athletes. On the dominance (Do) variable, there was a significant difference with the varsity athletes and upper-class non-athletes scoring higher than the freshman athletes and non-athletes. With respect to the social responsibility ( $R e$ ) variable, the upper-class non-athletes scored significantly higher than the varsity athletes and freshman athletes and non-athletes. On the depression (D) variable, varsity athletes in only individual sports scored significantly higher than athletes in only team sports. Athletes in varsity individual sports scored significantly higher on the psychasthenia (Pt) variable than those in both team and individual varsity sports. From the items of the MMPI, twenty-two were selected that discriminated significantly between poor and good competitors. 
Keogh (8) and Rasch, Hunt, and Robertson (22) expressed doubts as to the significance of Booth's (2) results reported in the study. In a rebuttal, Booth (3) defended the results of the above study by once again stating his results and presenting his data. The conclusions were once again quite obvious.

Keogh (9) attempted to differentiate between the terms "motor ability" and "athletic participation" in their relationship to personality. The California Psychological Inventory (CPI) was administered to 167 junior and senior male college students classified as to level of motor ability and participation in athletics. Athletic participation did not appear to have any effect upon the personality measures studied.

In an attempt to compare high school athletes and nonathletes on their personality profiles, as measured by the Minnesota Multiphasic Personality Inventory (MMPI), Slusher (26) selected high school athletes and compared them with non-athletes from the same population. The subjects were also compared on intelligence quotients. The results indicated the athletic groups to be higher on the categories of depression (D), hysteria (hy), and psychasthenia (Pt); however, they were lower on the categories of psychopathic deviation (Pd) and paranoia ( $\mathrm{Pa}$. The athletic groups were significantly lower in regard to femininity and intelligence. They were, however, significantly higher in regard to 
hypochondriasis; this was true for all the athletes except swimmers. There was no difference between the athletic and non-athletic groups on hypomania (Ma) and the validity scale $(K)$.

Kroll (11), Johnsgard and Ogilvie (6), Malumphy (13), Williams, Hoepner, Moody, and Ogilvie (30), and Ogilvie (17) added further support to the idea of a definite personality structure for an athlete; however, in a later study, Kroll and Carlson (12), working with karate participants and using the Cattell 16 PF Questionnaire, found no profile components or patterns which differentiated between levels of karate participation and proficiency, or the karate participants and the normal population.

Whiting and Stembridge (29), working with college and high school persistent non-swimmers and using the Maudsley Personality Inventory, concluded that more concern should be given the personality development as well as the skill development of the persistent non-swimmer if better and faster results are to be achieved.

Bosco (4), Schendel (23), Peterson, Weber, and Trousdale (20), Newman (16), and Pyecha (21) conducted studies which add strength to the theory that personality differences do exist between athletes and non-athletes and between athletes or participants in one sport as compared to participants in other sports. 
However, Berger and Littlefield (1) and Singer (25) completed studies whose findings seem to refute the personality theory suggested by the previous studies. The results found no significant difference between football athletes and non-athletes on personality, and only a few traits were significant between and within baseball and tennis players on personality characteristics. Likewise, Werner and Gottheil (28) used the Cattell 16 PF Questionnaire on a group of 340 athletes and 116 athletic nonparticipants in an attempt to determine whether or not participation in competitive sports contributed to the development of desirable personality characteristics. Their findings did not support the view that collegiate athletics had a significant influence upon personality structure. These studies lend support to Secord and Backman's statement that "Clinical psychologists, personality theorists, and most other students of individual behavior commonly assume that a person gradually forms characteristic behavior patterns which become more and more resistant to change with the passage of time" (24, p. 21).

Koocher (10) wanted to show that one's self-esteem is enhanced by increasing competence in one's immediate environment. Using the Index of Adjustment and Values in a pretest and posttest situation on sixty-five boys between seven and fifteen years of age, it was found that success in learning to swim reduced significantly the discrepancy between the 
ideal self and the self-concept. Those subjects who failed to master the task of swimuing and the controls who already knew how to swim failed to experience any significant change in the ideal self and self-concept discrepancies.

Ogilvie and Tutko (19) along with Lee Lyon developed the Athletic Motivation Inventory in an attempt to measure personality traits common to most successful athletes. Approximately 15,000 athletes from the high school participant to the professional have been tested. The results from their testing indicated that athletes who survive the high attrition rate connected with (sports competition seem to have a great need for achievement and set high goals for themselves. They respect authority, are dominant, organized, and orderly. They are trustworthy, have high psychological endurance, self-control, low anxiety levels, and are able to express aggression to a higher degree than other persons. Athletes have a low need for affiliation along with a low need to take care of others. They do not seem to be very interested in receiving support and concern from others. However, the researchers found no support for the old tradition that sports participation tends to build character. It seems that lathletic competition may limit one's growth in some areas. The results of Ogilvie and Tutko's study agreed with the results of Johnson, Hutton, and Johnson (7) in respect to a need for achievement, setting high goals for themselves, and extreme aggression; they disagree with 
respect to anxiety levels and self-control. These results also added support to the findings of Kroll (1I), Johnsgard and Ogilvie (6), Malumphy (13), Williams, Hoepner, Moody, and Ogilvie (30), and Ogilvie (7), which supported the idea of a definite personality structure for an athlete. 


\section{CHAPTER BIBLIOGRAPHY}

1. Berger, Richard A. and Donald H. Littlefield, "Comparison Between Football Athletes and Nonathletes on Personality," Research Quarterly, XI (December, 1969), 663-665.

2. Booth, E. G., Jr., "Personality Traits of Athletes as Measured by the MMPI," Research Quarterly, XXIX (May, 1958), 127-138.

3. , "Personality Traits of Athletes as Measured by the MMPI: A Rebuttal," Research

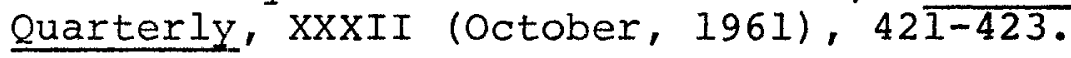

4. Bosco, James S., "The Physical and Personality Characteristics of Champion Male Gymnasts," unpublished doctoral dissertation, University of IIlinois, Urbana, Illinois, 1962 .

5. Edwards, Allen L., The Measurement of Personality Traits by Scales and Inventories, New York, Holt, Rinehart and Winston Inc., 1970.

6. Johnsgard, Keith $W$. and Bruce C. Ogilvie, "The Competitive Racing Driver," The Journal of Sports Medicine and Physical Fitness, VIII (June, 1968), 87-95.

7. Johnson, Warren R., Daniel C. Hutton, and Granville B. Johnson, Jr., "Personality Traits of Some Champion Athletes as Measured by Two Projective Tests: Rorschach and $\mathrm{H}-\mathrm{T}-\mathrm{P}, "$ Research Quarterly, XXV (December, 1954), 484-485.

8. Keogh, Jack, "Comments on the Selection of Data for Presentation," Research Quarterly, XXXI (May, 1960), 240 .

9.

"Relationship of Motor Ability and Athletic Participation in Certain Standardized Personality Measures," Research Quarterly, XXX (December, 1959), 438-4 45 .

10. Koocher, Gerald P., "Swimming, Competence, and Personality Change," Journal of Personality and Social Psychology, XVIII (June, $1 \overline{971)}, 27 \overline{5-278}$. 
11. Kroll, Walter, "Sixteen Personality Factor Profiles of Collegiate Wrestlers," Research Quarterly, XXXVIII (March, 1967), 49-57.

12. and B. Robert Carlson, "Discriminant Function and Hierarchical Grouping Analysis of Karate Participants' Personality Profiles," Research Quarterly, XXXVIII (October, 1967), 405411.

13. Malumphy, Theresa M., "Personality of Women Athletes in Intercollegiate Competition," Research Quarterly, XXXIX (October, 1968), 610-620.

14. Morgan, William P., "Fact and Fancy: Separating Scientific Foundations from Unsupported Claims for Psychological, Sociological, and Physiological Benefits of Physical Exercise and Formal Physical Education-Psychological Considerations," Journal of Health, Physical Education and Recreation, XXXIX (November-December, 1968), 25-40.

15. Nelson, Dale 0 . and Philip Langer, "Getting to Really Know Your Players," Athletic Journal, XLIV (September, 1963), 39.

16. Newman, EarI N., "Personality Traits of Faster and Slower Competitive Swimmers," Research Quarterly, XXXIX (December, 1968), 1049-1053.

17. Ogilvie, Bruce C., "Psychological Consistencies Within the Personality of High-Level Competitors," The Journal of the American Medical Association, CCV (September 9,1968 ), 780-786.

18. "The Unconscious Fear of Success," Quest, X (MaY, 1968), 35-39.

19. and Thomas A. Tutko, "Sport: If You Want to Build Character, Try Something Else," Psychology Today, V (October, 1971), 61-63.

20. Peterson, Sheri L., Jerome C. Weber, and William W. Trousdale, "Personality Traits of Women in Team Sports vs. Women in Individual Sports," Research Quarterly, XXXVIII (December, 1967), 686-690.

21. Pyecha, John, "Comparative Effects of Judo and Selected Physical Education Activities on Male University Freshmen Personality Traits," Research Quarterly XLI (October, 1970), 425-431. 
22. Rasch, Philip J., M. Briggs Hunt, and Port G. Robertson, "The Booth Scale as a Predictor of Competitive Behavior of College Wrestlers," Research Quarterly, XXXI (March, 1960), 117-118.

23. Schendel, Jack, "Psychological Differences Between Athletes and Nonparticipants in Athletics at Three Educational Levels," Research Quarterly, XXXVI (March, 1965), 52-67.

24. Secord, Paul F. and Carl W. Backman, "Personality Theory and the Problem of Stability and Change in Individual Behavior: An Interpersonal Approach," Psychological Review, LXVIII (January, 1961), 2132.

25. Singer, Robert N., "Personality Differences Between and Within Baseball and Tennis Players," Research Quarterly, XL (October, 1969), 582-588.

26. Slusher, Howard S., "Personality and Intelligence Characteristics of Selected High School Athletes and Nonathletes," Research Quarterly, XXXV (December, 1964), 539-545.

27. Thune, John B., "Personality of Weightlifters," Research Quarterly, XX (October, 1949), 296-306.

28. Werner, Alfred $c$. and Edward Gottheil, "Personality Development and Participation in College Athletics," Research Quarterly, XXXVII (March, 1966), 126-131.

29. Whiting, H. T. A. and D. E. Stembridge, "Personality and the Persistent Non-swimmer," Research Quarterly, XXXVI (October, 1965), $\overline{348-356}$.

30. Williams, Jean M., Barbara J. Hoepner, Dorothy L. Moody, and Bruce C. Ogilvie, "Personality Traits of Champion Level Female Fencers," Research Quarterly, XLI (October, 1970), 446-453. 


\section{CHAPTER III}

\section{PROCEDURES}

Implications resulting from psychological research of participation in sports activities have made available much new and beneficial information for the individuals teaching in physical education and athletics. This study attempted to add new insights into the psychological aspects of gymnastics by examining selected personality factors of participants.

\section{Selection of Subjects}

The subjects for this study were thirty male gymnasts on a high school gymnastic team, thirty high school male non-athletes, and thirty high school male athletes involved in football for the 1971-72 school year. The non-athletes were individuals enrolled in boys' physical education but not involved in any varsity sport for the 1971-72 school year. The gymnasts were the ten best participants as determined by their coach at Trinity High School in Euless, Texas, and the twenty best participants as determined by their coach at I. D. Bell High School in Hurst, Texas. Ten nonathletes and ten football athletes were also obtained from Trinity High School, and twenty non-athletes and twenty football athletes were obtained from I. D. Bell High School. 
The non-athletes and football athletes were selected at random from the class rolls of boys' physical education and the football team respectively. The table of random numbers by Owen (4), as explained by Freund and Williams (2, p. 182), was used to select the non-athletes and football athletes. All subjects were between the ages of fifteen and eighteen. Every attempt was made to match the subjects as closely as possible on age.

\section{Selection of Tests}

Examination and comparison of the personality characteristics of these subjects was accomplished by Cattell's Ir. - Sr. High School Personality Questionnaire, Form A, 1968-69 edition. The fourteen primary factors measured by this inventory are: A, reserved vs. warmhearted; B, dull vs. bright; C, affected by feelings vs. emotionally stable; D, undemonstrative vs. excitable; E, obedient vs. assertive; F, sober vs. enthusiastic; G, disregards rules vs. conscientious; H, shy vs. adventurous; $I$, tough-minded vs. tenderminded; J, zestful vs. circumspect individualism; 0 , selfassured vs. apprehensive; $Q_{2}$, sociably group-dependent vs. self-sufficient; $Q_{3}$, uncontrolled vs. controlled; $Q_{4}$ ' relaxed vs. tense. A more complete description of these factors can be obtained from Appendix A. 
Experimental Design

When the subjects had been assembled, each was given the questionnaire booklet and an answer sheet. Directions for answering the questions and using the answer sheet were available on the booklet; however, these directions were read aloud to each group. Any questions concerning the administration of the questionnaire were answered. To satisfy the curiosity of these individuals as to why they were chosen as subjects, an explanation was given which stated that they had been selected to participate in a research study. The subjects were instructed to do exactly as the directions on the test booklet indicated and were assured that they would answer the questionnaire only once. They were also assured that the results of the questionnaire would have no effect upon their school or personal life in any way. Appreciation was expressed to the subjects for their cooperation.

When everyone had completed the answer sheet, they were collected along with the booklets. The purpose of this study was explained and the group was dismissed.

of the ninety subjects tested, eighteen were tested within a week of the initial testing sessions for their high school. The late subjects were not given any special attention or considerations during their test administration. Each individual was tested once. 


\section{Analysis of Data}

The answer sheets were hand scored using the method outlined by Cattell (1, pp. 17-18) to obtain a raw score for each individual on each trait measured. These raw scores were then converted to standard scores as provided for by Cattell (1, p. 25). Each subject's scores on the traits contributed toward his group's mean score on the same traits. The statistical application used on the mean score for each trait among the three groups was a one-way, completely randomized analysis of variance, using the F ratio. The test chosen for determining the source of variation was the Newman-Keuls multiple comparisons test (3, p. 91). This test is neither too liberal nor too conservative in revealing significant differences. The groups were compared on each trait in an attempt to determine any significant differences between the gymnastic group and the football and non-athletic groups. 
1. Cattell, Raymond B. and Mary D. L. Cattell, Handbook for the Jr.-Sr. High School Personality Questionnaire, Champaign, Illinois, Institute for Personality and Ability Testing, 1969.

2. Freund, John E. and Frank J. Williams, Elementary Business Statistics: The Modern Approach, Englewood Cliffs, New Jersey, Prentice-Hall, Inc., 1964.

3. Kirk, Roger E., Experimental Design: Procedure for the Behavioral Sciences, Belmont, California, Brooks/ Cole Publishing Company, 1968.

4. Owen, Donald B., Handbook of Statistical Tables, Reading, Massachusetts, Addison-Wesley Publishing Company, Inc., 1962. 
CHAPTER IV

ANALYSIS OF THE DATA

The statistical analysis of data collected on ninety subjects tested by Cattell's Jr.-Sr. High School Personality Questionnaire is presented in this chapter.

Answers to several stated questions were sought through the study. The first question asked whether personality differences existed between the gymnastic group and the nonathletic group. The results indicated nonsignificant $F$ ratios on thirteen of the fourteen factors measured. A significant $F$ ratio at the .01 level of confidence was derived on factor B (dull vs. bright), as indicated in Table I. The Newman-Keuls multiple comparisons test identified the significance as existing between the gymnastic group and the non-athletic group. Table II presents these data. The gymnastic group scored significantly higher on factor $B$ than the non-athletic group. The higher mean score for the gymnastic group on this factor indicated significantly higher intelligence for the gymnasts when compared to the non-athletes. Although a significant difference was found to exist between these two groups, it should be indicated that the mean score for each group on factor $B$ was within the average range of ability established by Cattell (2) 
TABLE I

GROUP MEANS OF STANDARD SCORES, STANDARD DEVIATIONS, AND F RATIOS FOR THE THREE GROUPS ON THE FOURTEEN FACTORS MEASURED

\begin{tabular}{|c|c|c|c|c|c|c|c|c|c|}
\hline \multirow[b]{2}{*}{ Factor } & \multicolumn{4}{|c|}{ Group* Means } & \multicolumn{4}{|c|}{ Group standard Deviation } & \multirow{2}{*}{$\begin{array}{c}\mathrm{F} \\
\text { Ratio }\end{array}$} \\
\hline & $I$ & II & III & IV & $I$ & II & III & IV & \\
\hline A & 5.69 & 5.37 & 5.44 & 5.50 & 2.14 & 1.83 & 2.07 & 2.00 & 0.22 \\
\hline$B$ & 6.06 & 5.99 & 4.45 & 5.50 & 1.57 & 1.72 & 2.27 & 2.00 & $7.07 * *$ \\
\hline $\mathrm{C}$ & 4.95 & 5.68 & 5.87 & 5.50 & 1.87 & 2.21 & 1.84 & 2.00 & 1.83 \\
\hline $\mathrm{D}$ & 5.78 & 4.85 & 5.88 & 5.50 & 1.76 & 1.69 & 2.38 & 2.00 & 2.51 \\
\hline$E$ & 5.09 & 5.89 & 5.51 & 5.50 & 2.19 & 1.93 & 1.85 & 2.00 & 1.19 \\
\hline$F$ & 5.83 & 5.39 & 5.27 & 5.50 & 2.24 & 2.01 & 1.74 & 2.00 & 0.65 \\
\hline G & 5.84 & 5.01 & 5.65 & 5.50 & 1.90 & 2.30 & 1.72 & 2.00 & 1.41 \\
\hline $\mathrm{H}$ & 5.18 & 5.90 & 5.42 & 5.50 & 1.97 & 2.06 & 1.96 & 2.00 & 1.03 \\
\hline$I$ & 5.92 & 5.37 & 5.21 & 5.50 & 2.50 & 1.99 & 1.34 & 2.00 & 1.03 \\
\hline$J$ & 5.79 & 5.28 & 5.42 & 5.50 & 1.99 & 1.89 & 2.15 & 2.00 & 0.52 \\
\hline 0 & 5.49 & 5.57 & 5.44 & 5.50 & 1.99 & 2.00 & 2.07 & 2.00 & 0.03 \\
\hline$Q_{2}$ & 5.87 & 5.52 & 5.11 & 5.50 & 2.12 & 2.10 & 1.76 & 2.00 & 1.10 \\
\hline$Q_{3}$ & 5.32 & 5.80 & 5.38 & 5.50 & 2.11 & 2.14 & 1.76 & 2.00 & 0.50 \\
\hline$Q_{4}$ & 5.54 & 5.96 & 5.00 & 5.50 & 1.82 & 1.92 & 2.19 & 2.00 & 1.73 \\
\hline
\end{tabular}

for this questionnaire. The gymnasts are required to maintain a passing grade average, which could have affected the results on this factor.

The second question asked whether personality differences existed between the gymnastic group and the football group. As indicated in Table II, the Newman-Keuls multiple 
TABLE II

GROUP MEANS OF STANDARD SCORES, MEAN DIFFERENCE, AND NEWMAN-KEULS RANGE PRODUCT ON FACTOR B

\begin{tabular}{c|c|c|c|c|c}
\hline \multirow{2}{*}{ Factor } & \multicolumn{3}{|c|}{ Group* Means } & \multicolumn{1}{c|}{$\begin{array}{c}\text { Mean } \\
\text { Difference }\end{array}$} & $\begin{array}{c}\text { Newman-Keuls } \\
\text { Test Level }\end{array}$ \\
\cline { 2 - 6 } & I & II & III & $1.61 * *$ & 1.47 \\
& 6.06 & & 4.45 & 0.07 & 1.29 \\
& 6.06 & 5.99 & & $1.54 * *$ & 1.29 \\
\hline
\end{tabular}
group, $\mathrm{N}=30 ;$ Group III, Non-athletic group, $\mathrm{N}=30$.

**Significant at the .01 level of confidence.

comparisons test yielded no significant difference between the mean scores for the gymnastic group and the football group.

The third question asked whether personality differences existed between the football group and the non-athletic group. A significant $F$ ratio existed on factor $B$ (dull vs. bright) at the .01 level of confidence, as indicated in Table I. The Newman-Keuls multiple comparisons test identified the significance as existing between the football group and the non-athletic group. Table II presents these data. The football group scored significantly higher on this factor at the .01 level of confidence. The higher mean score for the football group on factor B indicated significantly higher intelligence for the football participants when compared to the non-athletes; however, it should be 
indicated that the mean score for each group on factor $B$, as was stated for the comparison between the gymnasts and non-athletes, was within the average range of ability. The football participants are required to maintain a passing grade average, which could have affected the results on this factor.

The differences among the groups on each trait are discussed below.

Factor A.--The gymnasts averaged higher than the nonathletes and football group, but the mean differences were not significant at the .05 level. The data indicated the gymnasts to be more warmhearted as opposed to reserved.

Factor B.--The gymnasts averaged slightly higher than the football group and significantly higher than the nonathletes. The football participants averaged significantly higher than the non-athletes. The data indicated the gymnasts and football participants to be brighter as opposed to dull.

Factor C.--The gymnasts averaged less than the nonathletes and football group, but the mean differences were not significant at the .0.5 level. The data indicated the gymnasts to be more affected by feelings as opposed to being emotionally stable.

Factor D. --The gymnasts averaged higher than the football group and lower than the non-athletic group, but the 
mean differences were not significant at the .05 level. The data indicated the gymnasts to be more excitable as opposed to undemonstrative.

Factor E.--The gymnasts averaged less than the football group and non-athletes, but the mean differences were not significant at the .05 level. The data indicated the gymnasts to be more obedient as opposed to assertive.

Factor F.--The gymnasts averaged higher than the football group and non-athletes, but the mean differences were not significant at the .05 level. The data indicated the gymnasts to be more enthusiastic as opposed to sober.

Factor G.--The gymnasts averaged higher than the nonathletes and football group, but the mean differences were not significant at the .05 level. The data indicated the gymnasts to be more conscientious as opposed to disregards rules.

Factor H.--The gymnasts averaged less than the football group and non-athletic group, but the mean differences were not significant at the .05 level. The data indicated the gymnasts to be more shy as opposed to adventurous.

Factor I.--The gymnasts averaged higher than the football group and non-athletes, but the mean differences were not significant at the .05 level. The data indicated the gymnasts to be more tender-minded as opposed to tough-minded. 
Factor J.--The gymnasts averaged higher than the nonathletes and football group, but the mean differences were not significant at the .05 level. The data indicated the gymnasts to possess circumspect individualism as opposed to zestfulness.

Factor 0.--The gymnasts averaged less than the football group and higher than the non-athletic group, but the mean differences were not significant at the .05 level. The data indicated the gymnasts to be more self-assured as opposed to apprehensive.

Factor $\underline{Q}_{2} \cdot--T h e$ gymnasts averaged higher than the football group and non-athletic group, but the mean differences were not significant at the .05 level. The data indicated the gymnasts to be more self-sufficient as opposed to sociably group-dependent.

Factor $\underline{Q}_{3}{ }^{-}-$The gymnasts averaged less than the football group and non-athletic group, but the mean differences were not significant at the .05 level. The data indicated the gymnasts to be more uncontrolled as opposed to controlled.

Factor $\underline{Q}_{4}{ }^{-}$-The gymnasts averaged less than the football group and higher than the non-athletic group, but the mean differences were not significant at the .05 level. The data indicated the gymnasts to be tense as opposed to relaxed. 
All of the means on the fourteen factors for the groups tested were within the average range of ability established for the questionnaire used in the present study.

\section{Comparison with Other Studies}

A comparison of the findings of this study with a similar study by Bosco (1), revealed that only a very slight similarity existed. The instrument of measurement for personality characteristics used by Bosco was the Cattell 16-Factor Personality Inventory, which is the adult version of the questionnaire used in the present study. He found the gymnasts to average significantly greater in respect to brightness and intelligence vs. dullness and low capacity, calmness and maturity vs. instability and emotional tendency, conventionality and seriousness vs. eccentricity and unconcerned attitude, confidence and unshakable demeanor vs. insecurity and anxiousness, criticism and experimentation vs. conservativeness and accepting demeanor, and control and exactness vs. laxness and unsureness. The only similarity between Bosco's results and the results of the present study was in relation to factor B (dull vs. bright). In both studies the gymnastic group scored significantly higher than the non-athletes; however, it should be recognized in making this comparison that Bosco's subjects were of college age (seventeen to twenty-six years) while the subjects in the present study were of high school age (fifteen to eighteen years). 


\section{CHAPTER BIBLIOGRAPHY}

1. Bosco, James S., "The Physical and Personality Characteristics of Champion Male Gymnasts," unpublished doctoral dissertation, University of Illinois, Urbana, Illinois, 1962.

2. Cattell, Raymond B. and Mary D. I. Cattell, Handbook for the Jr.-Sr. High School Personality Questionnaire, Champaign, IIIinois, Institute for Personality and Ability Testing, 1969. 


\section{CHAPTER V \\ SUMMARY, CONCLUSIONS, AND \\ RECOMMENDATIONS}

Summary

The purpose of this study was to compare personality characteristics of high school male gymnasts to the personality characteristics of high school football athletes and non-athletes. An attempt was made to answer three specific questions:

I. Do personality differences exist between the gymnastic group and the non-athletic group?

II. Do personality differences exist between the gymnastic group and the football group?

III. Do personality differences exist between the football group and the non-athletic group?

The subjects in this study were selected from Trinity High School in Euless, Texas, and L. D. Bell High School in Hurst, Texas. Ten gymnasts, ten football athletes, and ten non-athletes were selected from Trinity High School, and twenty gymnasts, twenty football athletes, and twenty nonathletes were selected from L. D. Bell High School. A total of ninety subjects were tested. All subjects were between 
the ages of fifteen and eighteen. Every attempt was made to match the subjects as closely as possible on age.

The instrument of measurement utilized was the Cattell Jr.-Sr. High School Personality Questionnaire, Form A, 196869 edition. This questionnaire was administered to each of the ninety subjects only once. Results were obtained from this one test administration.

The statistical application applied to the means for each group was a one-way, completely randomized analysis of variance using the $\mathrm{F}$ ratio. The test utilized for determining the source of variation was the Newman-Keuls multiple comparisons test. The answer sheets were scored using a stencil key to obtain a raw score for each trait. The raw scores for each individual tested were transformed to standard scores for the statistical evaluation.

\section{Findings}

Based on the analysis of the data for this study, the findings of the study concerning Questions I, II, and III were as follows:

1. A significant mean difference existed between the gymnastic group and non-athletic group on factor B (dull vs. bright). The gymnastic group scored significantly higher than the non-athletic group at the .01 level of confidence, indicating the gymnasts to be significantly more intelligent than the non-athletes; however, it should be indicated that 
the gymnasts must maintain a passing grade average to be an athlete. No significant mean differences were found to exist between these two groups on any of the remaining factors measured.

2. No significant mean difference was found to exist between the gymnastic group and the football group on any of the fourteen factors measured.

3. A significant mean difference existed between the football group and non-athletic group on factor B (dull vs. bright). The football group scored significantly higher than the non-athletic group at the .01 level of confidence, indicating the football participants to be significantly more intelligent than the non-athletes; however, it should be indicated that the football participants must maintain a passing grade average to be an athlete. No significant mean difference was found to exist between these two groups on any of the remaining factors measured.

4. No significant mean differences were found to exist among the three groups on any of the fourteen factors measured except factor B (dull vs. bright).

\section{Conclusions}

Based on the analysis of the data for this study, the following conclusions were drawn:

1. Individuals engaged in competitive gymnastics in senior high school are significantly more intelligent than 
senior high school individuals not engaged in any sporting activity as a team member.)

2. Competitive senior high school gymnasts are not significantly more intelligent than competitive senior high school football participants.

3. Individuals engaged in competitive senior high school football are significantly more intelligent than senior high school individuals not engaged in any sporting activity as a team nember.

4. There are no significant differences among the three groups on thirteen of the fourteen personality factors measured. Groups of individuals appear to be more alike than different in their personality characteristics.

\section{Recommendations}

Based on the present study, recommendations for further study in this area are as follows:

1. Further investigations should be conducted to include more high school state and national championship level gymnasts than were included in the present study.

2. Further investigations should include a non-athletic group of individuals who have not been involved in gymnastics in any way. Some participation in gymnastics by the non-athletic group could produce biased results. 
3. Further investigations should be conducted which employ the use of a different instrument of personality measurement in an attempt to determine whether the results of the present study prevail. 


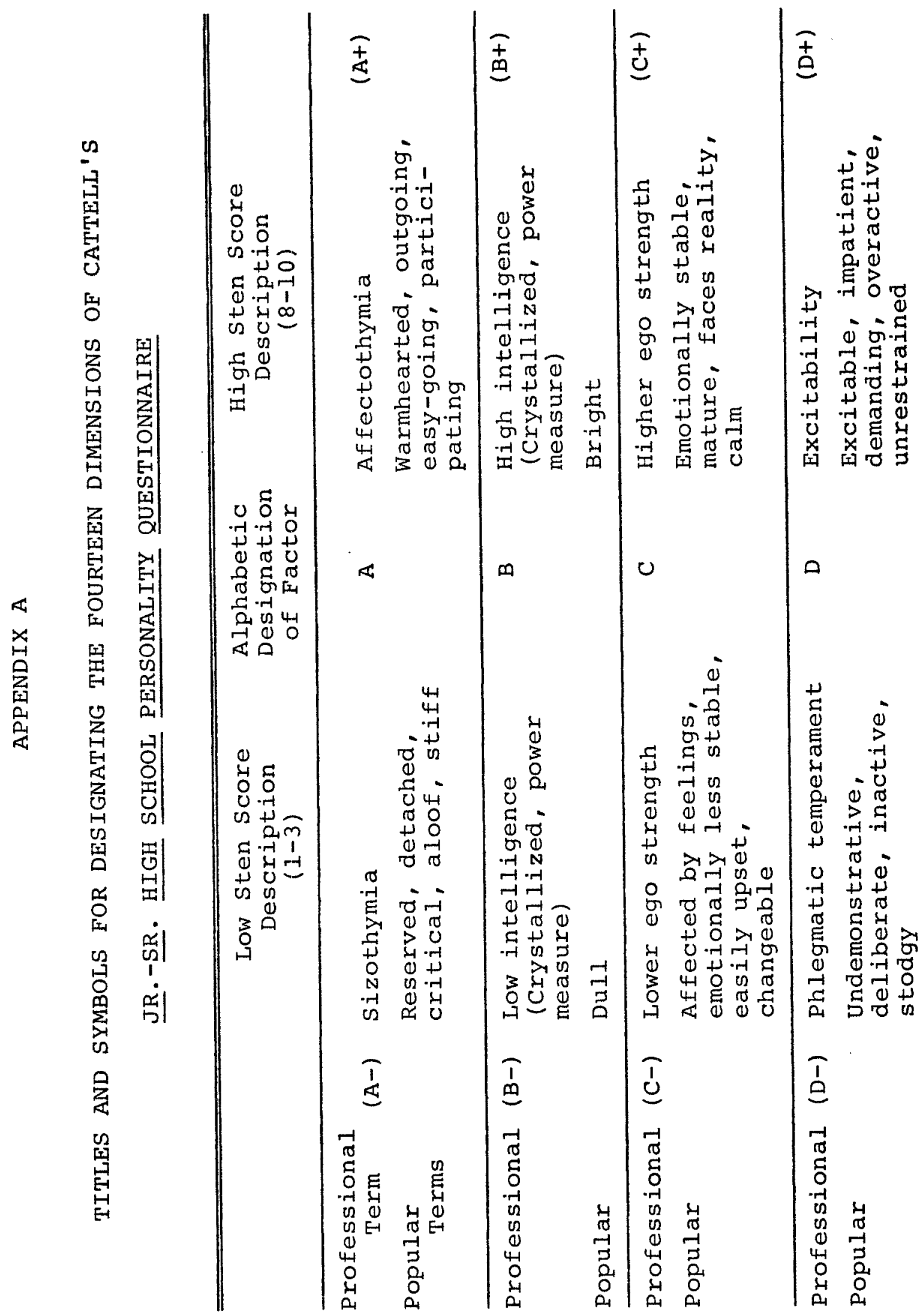




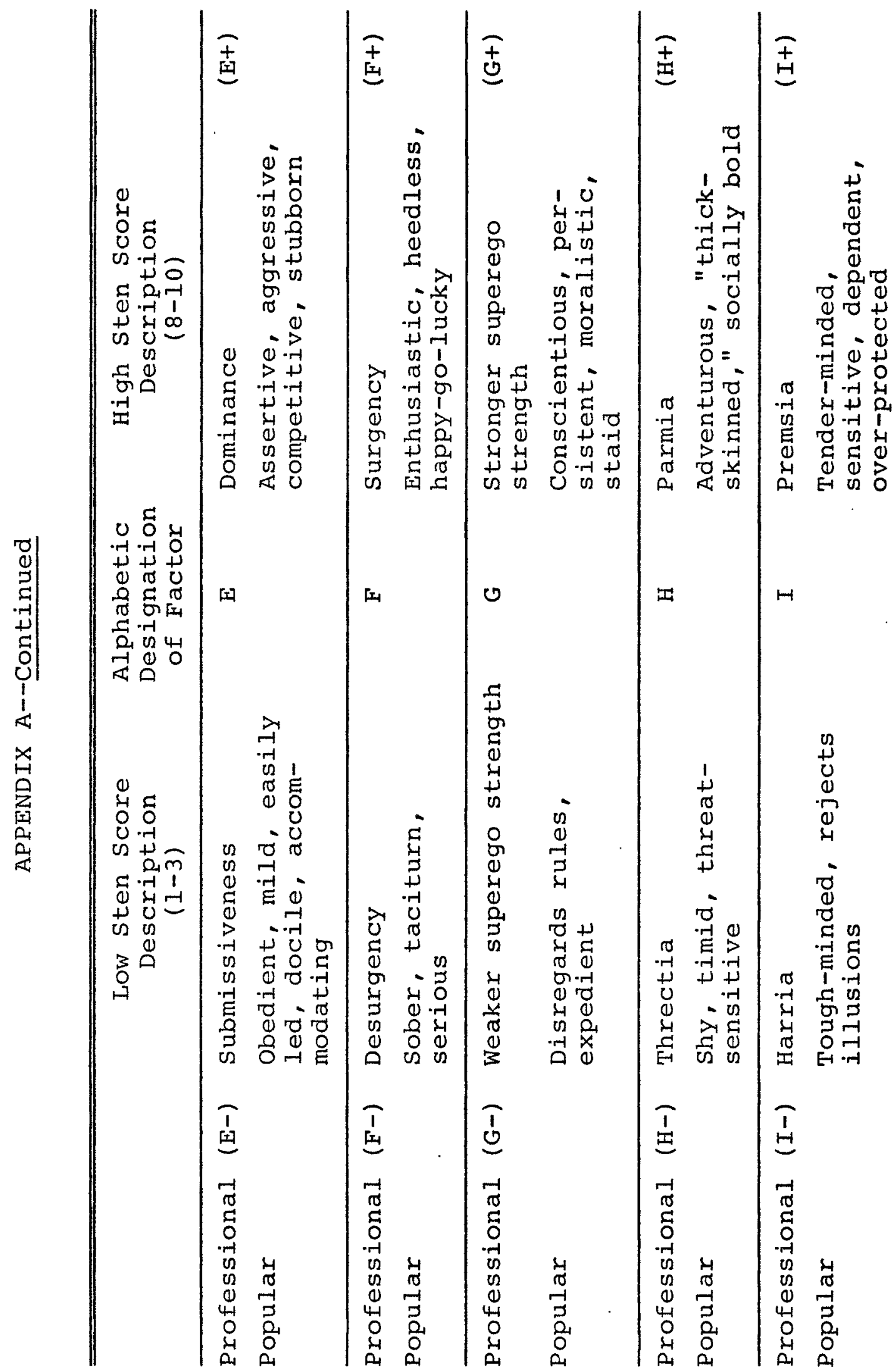




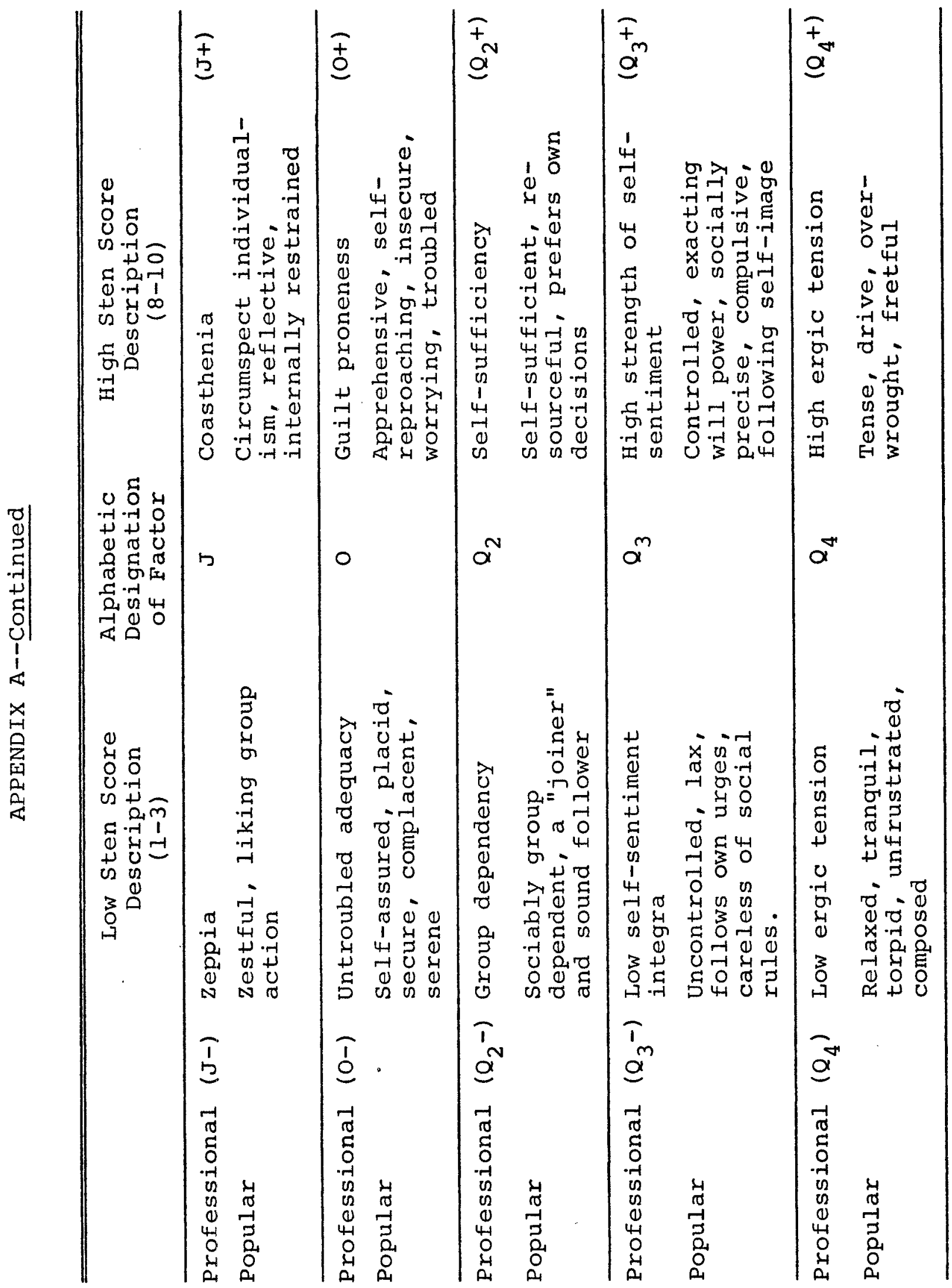




\section{BIBLIOGRAPHY}

\section{Books}

Cattell, Raymond B., The Scientific Analysis of Personality, Baltimore, Maryland, Penguin Books, Inc. 1965.

and Mary D. I. Cattell, Handbook for the Jr.-Sr. High School Personality Questionnaire, Champaign, IIIinois, Institute for Personality and Ability Testing, 1969.

Cratty, Bryant J., Movement Behavior and Motor Learning, Philadelphia, Lea and Febiger, $1 \overline{967 .}$

, Psychology and Physical Activity, Englewood Cliffs, New Jersey, Prentice-Hall, Inc., 1968.

DeCarlo, Tom, Handbook of Progressive Gymnastics, Englewood Cliffs, New Jersey, Prentice-Hall, Inc., 1963.

Duncan, Ray $O$. and Helen B. Watson, Introduction to Physical Education, New York, The Ronald Press Company, 1960.

Edwards, Allen L., The Measurement of Personality Traits by Scales and Inventories, New York, Holt, Rinehart and Winston, Inc., 1970.

Freund, John E. and Frank J. Williams, Elementary Business Statistics: The Modern Approach, Englewood Cliffs, New Jersey, Prentice-Hall, Inc., 1964.

Kirk, Roger E., Experimental Design: Procedures for the Behavioral Sciences, Belmont, California, Brooks/Cole Publishing Company, 1968.

Owen, Donald B., Handbook of Statistical Tables, Reading, Massachusetts, Addison-Wesley Publishing Company, Inc., 1962 .

Oxendine, Joseph B., Psychology of Motor Learning, New York, Appleton-Century-Crofts, $19 \overline{68}$. 


\section{Articles}

Berger, Richard A. and Donald H. Littlefield, "Comparison Between Football Athletes and Nonathletes on Personality," Research Quarterly, XI (December, 1969), 663-665.

Booth, E. G., Jr., "Personality Traits of Athletes as Measured by the MMPI," Research Quarterly, XXIX (May, 1958), 127-138.

, "Personality Traits of Athletes as Measured by the MMPI: A Rebuttal," Research Quarterly, XXXII (October, 1961), 421-423.

Johnsgard, Keith $W$. and Bruce C. Ogilvie, "The Competitive Racing Driver," The Journal of Sports Medicine and Physical Fitness, VIII (June, 1968), 87-95.

Johnson, Warren R., Daniel C. Hutton, and Granville B. Johnson, Jr., "Personality Traits of Some Champion Athletes as Measured by Two Projective Tests: Rorschach and $\mathrm{H}-\mathrm{T}-\mathrm{P}, "$ Research Quarterly, XXV (December, 1954), $484-485$.

Keogh, Jack, "Comments on the Selection of Data for Presentation," Research Quarterly, XXXI (May, 1960), 240.

, "Relationship of Motor Ability and Athletic Participation in Certain Standardized Personality Measures," Research Quarterly, XXX (December, 1959), 438445 .

Koocher, Gerald P., "Swimming, Competence, and Personality Change," Journal of Personality and Social Psychology, XVIII (June, 1971), 275-278.

Kroll, Walter, "Sixteen Personality Factor Profiles of Collegiate Wrestlers," Research quarterly, XXXVIII (March, 1967), 49-57.

and B. Robert Carlson, "Discriminant Function and Hierarchial Grouping Analysis of Karate Participants' Personality Profiles," Research Quarterly, XXXVIII (October, 1967), 405-4i1.

Malumphy, Theresa M., "Personality of Women Athletes in Intercollegiate Competition," Research Quarterly, XXXIX (October, 1968), 610-620. 
Morgan, William P., "Fact and Fancy: Separating Scientific Foundations from Unsupported Claims for Psychological, Sociological, and Physiological Benefits of Physical Exercise and Formal Physical Education-Psychological Considerations," Journal of Health, Physical Education and Recreation, XXXXX (November-December, 196 $6 \overline{8), 25-40 .}$

Nelson, Dale 0 . and Philip Langer, "Getting to Really know Your Players," Athletic Journal, XLIV (September, $1963), 39$.

Newman, Earl N., "Personality Traits of Faster and slower Competitive Swimmers," Research Quarterly, XXXIX (December, 1968), 1049-1053.

Ogilvie, Bruce C., "Psychological Consistencies within the Personality of High-Level Competitors," The Journal of the American Medical Association, CCV (september 9,

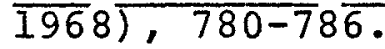

$\mathrm{X}$ (May, 1968), 35-39.

, "The Unconscious Fear of Success," Quest, and Thomas A. Tutko, "Sport: If You Want to Build Character, Try Something Else," Psychology Today, V (October, 1971), 61-63.

Peterson, Sheri L., Jerome C. Weber, and William W. Trousdale, "Personality Traits of Women in Team Sports vs. Women in Individual Sports," Research Quarterly, XXXVIII (December, 1967), 686-690.

Pyecha, John, "Comparative Effects of Judo and Selected Physical Education Activities on Male University Freshman Personality Traits," Research Quarterly, XLI (October, 1970), 425-43I.

Rasch, Philip J., M. Briggs Hunt, and Port G. Robertson, "The Booth Scale as a Predictor of Competitive Behavior of College Wrestlers," Research Quarterly, XXXI (March, 1960), 117-118.

Schendel, Jack, "Psychological Differences Between Athletes and Nonparticipants in Athletics at Three Educational Levels," Research Quarterly, XXXVI (March, 1965), 5267 .

Secord, Paul F. and Carl W. Backman, "Personality Theory and the Problem of Stability and Change in Individual Behavior: An Interpersonal Approach," Psychological Review, LXVIII (January, 1961), 21-32. 
Singer, Robert N., "Personality Differences Between and Within Baseball and Tennis Players," Research Quarterly, XL (October, 1969), 582-588.

Slusher, Howard S., "Personality and Intelligence Characteristics of Selected High School Athletes and Nonathletes," Research Quarterly, XXXV (December, 1964), 539-545.

Thune, John B., "Personality of Weightlifters," Research Quarterly, Xx (October, 1949), 296-306.

Werner, Alfred C. and Edward Gottheil, "Personality Development and Participation in College Athletics," Research Quarterly, XXXVII (March, 1966), 126-131.

Whiting, H. T. A. and D. E. Stembridge, "Personality and the Persistent Non-swimmer," Research Quarterly, XXXVI (October, 1965), 348-356.

Williams, Jean M., Barbara J. Hoepner, Dorothy L. Moody, and Bruce C. Ogilvie, "Personality Traits of Champion Level Female Fencers," Research Quarterly, XLI (October, $1970), 446-453$.

Unpublished Material

Bosco, James S., "The Physical and Personality Characteristics of Champion Male Gymnasts," unpublished doctoral dissertation, Department of Physical Education, University of Illinois, Urbana, Illinois, 1962. 